\title{
Caustic stenosis of mid esophagus, late rehabilitation in a six years old girl
}

Keywords: caustic ingestion, caustic burns, esophageal stenosis, esophageal caustic stenosis, esophagus rehabilitation.

Abbreviations: RBES, refractroy benign esophageal stricture; BES, Benign esophageal strictures; EBD, esophageal bougie or ballon dilation

\section{Introduction}

Aim: Describe late benign mid esophagus complicated stenosis (1$2 \mathrm{~mm}$ diameter by $4 \mathrm{~cm}$ length) rehabilitation in a six years old girl.

Caustic ingestion in childhood can produce severe local and systemic signs, symptoms and complications: drooling, swallowing pain, solid and liquid dysphasia, local and systemic infection and perforation. In this patient, mid esophagus stenosis rehabilitation begins at day 51 after caustic ingestion. We describe the long and complicated road she has to pass in her rehabilitation, after 57 esophageal dilations with general anesthesia and endoscopy every week to two or three esophageal dilations per week, an esophageal metallic expandable covered stent, with anti-reflux mechanism, was put in the two distal thirds of the esophagus, it lasted a little bit more than two months, when it migrated to stomach, it was retired and esophageal dilations were reinitiated.

\section{Case}

A six year old girl accidentally ingested a liquid caustic, it was on a soda recipient, she drink on june-26-2017, immediately she begin with droolong and severe mouth pain. Endoscopy revealed white fibrinous plaques, erythematic and hemorrhage in all espohagus mucosa. She was put on fast about one week, a surgical gastrostomy was done, it was closed in about two weeks; she was in other city. On august 16-2017, 51days after caustic ingestion, she arrived to our hospital; at that time, she has three days with dysphagia to solids and liquids, she has acrocianosis and choked with her saliva. The first nine days she is on the hospital, and are done the first three esophageal stenosis dilations; after discharged, she is maintained with esophageal dilations three, two or one per week.

In the first endoscopy, a punctate stenosis is documented, al $19 \mathrm{~cm}$ from superior incisors, an alambric guide wire is passed and followed by $5 \mathrm{~mm}$ Savary-Guilliard dilator, at this time, she developed gastric dilation, as air passed through the esophageal stenosis, but could not get out; abdominal circumference severely increased; pediatric surgeon evaluated the patient, he determined she only has deglutated air into stomach. After several esophageal dilations, the diameter increased from $1-2 \mathrm{~mm}$ to $18 \mathrm{~mm}$, the frecuency diminished from three to two per week, but the esophageal diameter diminished from 18 to $8 \mathrm{~mm}$, so, the frecuency of esophageal dilations increased once again; two more times we try to have two dilations per week, the
Volume 9 Issue 4 - 2018

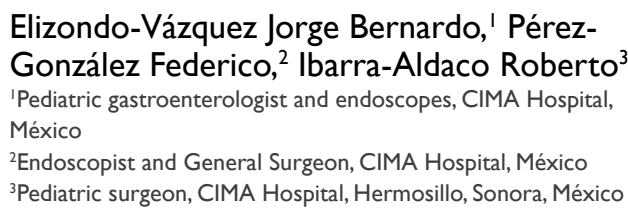

Correspondence: Elizondo-Vázquez Jorge Bernardo, Pediatric gastroenterologist and endoscopes, CIMA Hospital, México, Email jelizondovazquez@gmail.com

Received: June 30, 2018| Published: August 10, 2018

problema is the esophageal diameter diminished to $8 \mathrm{~mm}$ from $18 \mathrm{~mm}$. After 57 esophageal dilations, on march-24-18 an expandible metalic esophageal stent, completely covered, with anti-reflux mechanism, with diameter of $20 \mathrm{~mm}$ by 10 length $\mathrm{cm}$ is put on two distal thirds of esophagus and proximal stomach.

She does not need esophageal dilation while stent was located on esphagus; it remained there just a little bit more than two months, after one and a half month, she begin with dysphagia to solids which; in three weeks, progress to dysphagia to liquids, until she could not pass nothing by mouth three days before she was carried to the hospital, on june-8-2018. Thoracic and abdominal X-rays demonstrated migration of the stent to stomach. Endoscopy revealed stricture of $8-9 \mathrm{~mm}$, with irregular surface, which bleed as endoscope, of $9.8 \mathrm{~mm}$, passed through stomach. The proximal part of stent is located to the antrum, and distal part is on proximal part of stomach body, with its body convexaly curved to front view of the endoscope. In retroflexion, the proximal part of the stent, located towards the antrum, let easily see the thread located inside of the stent, it was grasped by foreign body forceps and pulled, the esophageal stent migrated to stomach was extracted without any complication.

While stent was in right place on esophagus, about month and a half, she eats solid foods without dysphagia; after that, in three weeks, she developed progressive dysphagia, from solids to liquids until she cannot pass even her saliva. The next weeks after stent was removed, she starts an esophageal dilation program, for the first time, after three dilation per week per two weeks, the esophageal stricture let continues with two dilations per week per two weeks, followed by one per week. One year after caustic ingestion (june-26-17), in which esophageal rehabilitiation begins 51 days after caustic ingestion (seven weeks and 2days) she still is on esophageal stricture dilation program (Figure 1-5). 


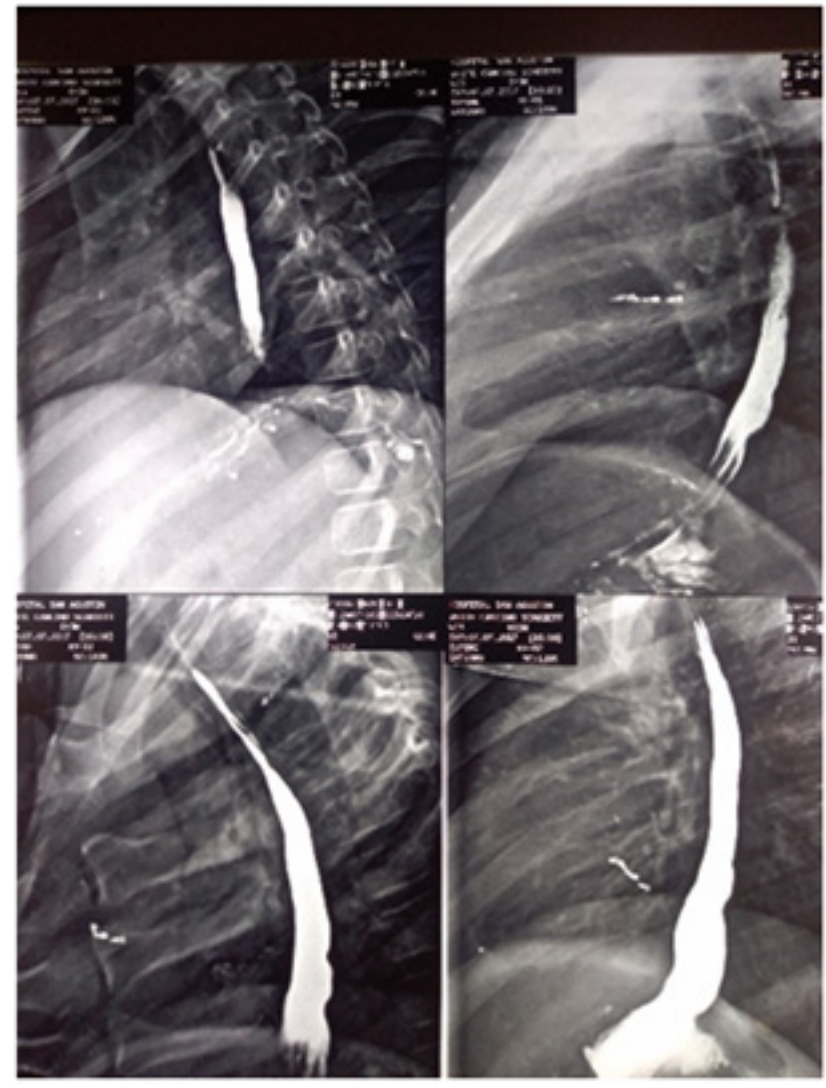

Figure I Esophagogram. July 7-17. No evidence of esophageal stricture 10days after liquid caustic ingestion.

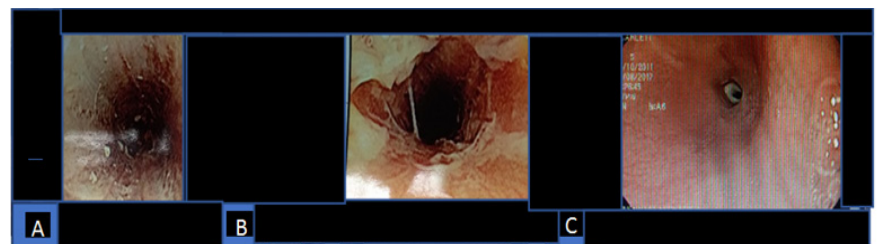

Figure $2 \mathrm{~A}$ and $\mathrm{B}$,esophagic caustic burns one day after liquid caustic ingestion. $C$, tiny lumen stricture al $19 \mathrm{~cm}$ from incisors, 5 I days after caustic ingestion.

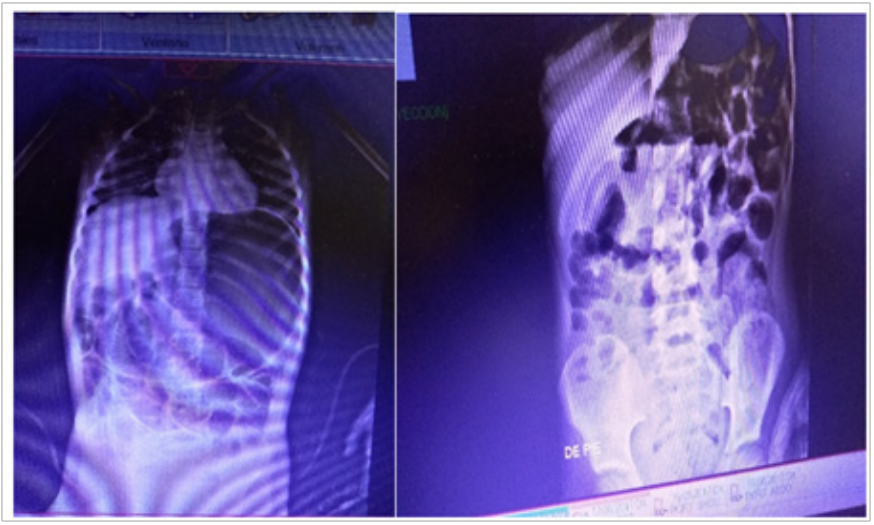

Figure3 A. Dilated stomach after passage of guide wire and first esophageal dilation. B. Normal gas distributiion on stomach and small bowel after 24hours.

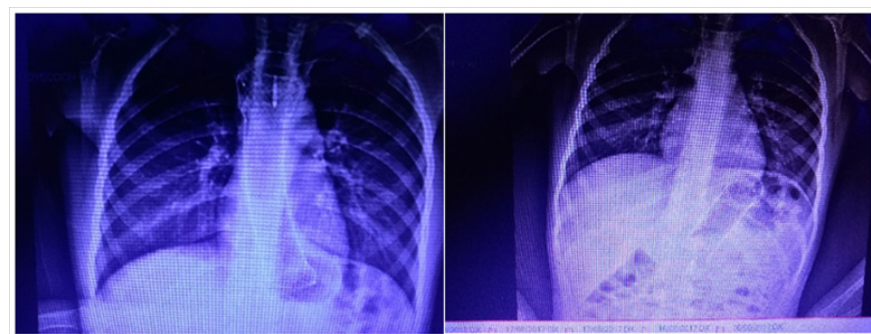

Figure $4 \mathrm{~A}$. Metalic expandible thoroughly covered esophagus stent in its correct place on esophagus, march-24-18. B. Migrated to stomach on june-8-2018.

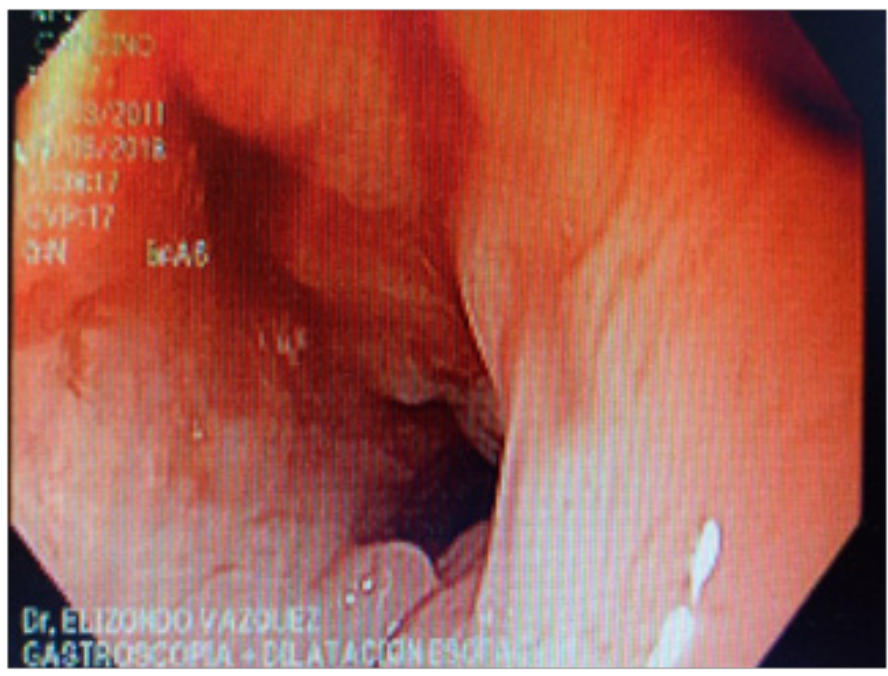

Figure 5 Endoscopic appearance after I Omonths dilation esophageal program, she has $14 \mathrm{~mm}$ lumen in mid esophagus with twice dilaton per week. Muscular layer is visible immediatly dilation to 15 and $18 \mathrm{~mm}$ with Savary-Guilliard dilators.

\section{Discussion}

The ingestion of corrosive agent's produces oropharyngeal and gastro-esophageal lesions, ranging from minor injuries to severe necrosis, depends on the agent that is ingested, its concentration and time of exposure. Of 473 patients, endoscopy found 379 with burn in esophagus $(80 \%)$ and 81 in stomach $(17 \%){ }^{1}$

This case corresponds to a late begining of esophageal stricture stenosis rehabilitation; as Gun mentioned, a group of esophageal strictures, which begin their rehabilitation six to 12 weeks after caustic ingestion, after one year of the accidentally ingested corrosive, remains on esophageal dilation program, and no one in the group of patients who begins their rehabilitation in the first weeks after caustic ingestion. ${ }^{2}$

Self expandible metalic thoroughly covered stent, with anti-reflux mechanism lasted in esophagus during six weeks, after that, it begins its slow stomach migration, it takes about three weeks, clinically the migration can be detected by dysphagia to solids; the mother expected until her dauther could even pass her saliva before she carry her to the hospital. Esophageal dilations, after stent extraction, were performed more easily if they are compared to esophageal dilations before its esophageal colocation: the passage of Savary-Guilliard 15 and $18 \mathrm{~mm}$ are passed easily, with less bleeding. 
The stricture in mid esophagus begins with 1 to two $\mathrm{mm}$ in diameter by $4 \mathrm{~cm}$ length. It needs three dilations per week; if there are two, the diameter diminish from 18 to $13-14 \mathrm{~mm}$, and if there is one per week, the diameter disminish from 18 to $8-9 \mathrm{~mm}$. Mid esophagus stricture mantains $13-14 \mathrm{~mm}$ diameter with two esophageal dilations per week. We expect dilations frecuency could be prolonged in next weeks. The placement of expandable prostheses, for one to four weeks, are useful in benign esophageal stenoses in children as Kramer described. ${ }^{3}$

An indication for stent placement is benign dysphagia as a consequence of refractroy benign esophageal stricture (RBES). Benign esophageal strictures (BES) can be caused by caustic ingestion. RBES are defined as an anatomic restriction becasue of a cicatricial luminal compromise or fibrosis resulting in clinical symptoms of dysphagia in the abscence of endoscopic evidence of inflammation; ${ }^{4}$ this may occur as the result of the inability to successfully remediate the esophageal narrowing to a diameter of, at least, $14 \mathrm{~mm}$ over five sessions at 2-week intervals, ${ }^{5}$ this girl has reached mid espohagus lumen of $13-14 \mathrm{~mm}$ with twice dilations per week previos to next dilation to 15 and $18 \mathrm{~mm}$.

Caustic BES is associated with a high risk of becoming refractory to treatment with repeated esophageal bougie or ballon dilation (EBD) ${ }^{6,7}$ The more time dilation program begin after caustic ingestion, more time needs esopahagel dilation program as happened with this girl. Stenting and use of mitomycin C $(0.4 \mathrm{mg} / \mathrm{mL})$ are technis used in caustic burns. ${ }^{8-11}$ Endoscopically placed stents is a useful alernative for the management of caustic esophageal strictures. ${ }^{12}$

The best measure to prevent esophageal stenosis is preventiion; but patients who arrived in the first six weeks of caustic ingestion, esophageal dilatiion program has to be initiatied because there are more possibilities that esophageal rehabilitition last less time than when arrived after 8-12weeks, as in this girl who arrived afeter 7 weeks.

\section{What is known}

i. Prevention is the best measure to avoid esophagus and stomach caustic burns.

ii. The first step to try to avoid refractary esophageal strictures is to begin as soon as possible esophageal dilation program, preferently before six weeks.

iii. A late begining of an esophagus dilation program with an esophgeal established stricture, can produce a refractory esophagus stricture.

\section{What should be known by clinicians}

i. An endoscopy evaluation has to be done in 24 to 48 hours of caustic ingestion.

ii. If there is no burn, no treatment is needed.

iii. If there is a caustic burn in esophagus and/or stomach, treatment must begin immediately: Airway permeability, vascular access, intravenous analgesic, steroids and antibiotics.

iv. Although some authors leave their patients one week on fast and with naso-gastric tube when they have caustic esophageal burns, in our institution, we give them food if they can pass it, and the esophageal rehabilitiation begins when stricture is detected, three to four weeks after caustic ingestion.

\section{Acknowledgements}

None.

\section{Conflict of interest}

The author declares no conflict of interest.

\section{References}

1. Dogan Y, Erkan T, Cokugras FC, et al. Caustic gastroesophageal lesions in childhood: an analysis of 473cases. Clinical Pediatrics. 2006;45(5):435438 .

2. Zhang C, Yu JM, Fan GP, et al. The use of retrievable self-expanding stent in treating childhood benign esophageal stictures. J Ped Surg. 2005;40(3):501-504.

3. Kramer RE, Quiros JA. Esophageal stents for severe strictures in youngchildren: experience, benefits and risks. Current gastroenterol Rep. 2010;12(3):203-210

4. Vermeulen BD, Siersema PD. Esophageal stenting in clinical practice: An overview. Curr Treat Options Gastro. 2018;16(2):260-73.

5. Kochman MI, McClave SA, Boyce HW. The refractory and the recurrent esophageal stricture: a definitiion. Gastrointest Endosc. 2005;62(3):474475 .

6. RepiciA, Small AJ, Mendelson A, et al. Natural history and management of refractory benign esophageal strictures. Gastrointest Endosc. 2016;84(2):222-228

7. Rodrigues-Pinto F, Pereira P, Ribeiro A, et al. Risk factors associated with refractor inessto esophageal dilatation for benign dysphagia. Eur $J$ Gastroenterol Hepatol. 2016;28(6):684-688.

8. Luigi Dall'Oglio, Tamara Caldaro, Francesca Foschia, et al. Endoscopic management of esophageal stenosis in children: New and traditional treatments. WJGE. 2016;8(4):212-219.

9. Sweed AS, Fawaz SA, Ezzat WF, et al. A prospective controlled study to assess the use of mitomycin $\mathrm{C}$ in improving the results of esophageal dilatation in post corrosive esophageal stricture in children. Int $J$ Pediatr Otorhinolaryngol. 2015;79(1):23-25.

10. El-Asmar KM, Hassan MA, Abdelkader HM, et al. Topical mitomycin $\mathrm{C}$ application is effective in management of localized caustic esophageal stricture: a double-blinded, randomized, placebo-controlled trial. J Pediatr Surg. 2013;48(7):1621-1627.

11. El-Asmar KM, Hassan MA, Abdelkader HM, et al. Topical mitomycin C can effectively alleviate dysphagia in children with long-segment caustic esophageal strictures. Dis Esophagus. 2015;28(5):422-427.

12. Nogales O, Clemente A, Aránzazu Caballero M. et al. Endoscopically placed stents: a useful alernative for the management of refractroy benign cervical esophageal stenosis. Rev Esp Enf Dig. 2017;109(7):510-515. 